\title{
Understanding the patient multidimensional experience: a qualitative study on coping in hospitals of Assistance Publique-Hôpitaux de Paris, France
}

\author{
This article was published in the following Dove Press journal: \\ Patient Preference and Adherence \\ 9 April 2015 \\ Number of times this article has been viewed
}

\section{Gérard Reach' \\ Denis Fompeyrine ${ }^{2}$ \\ Carole Mularski \\ 'Department of Endocrinology, Diabetes and Metabolic Diseases, Avicenne Hospital APHP and EA 34I2, CRNH-IdF, Paris I 3 University, Bobigny, France; ${ }^{2}$ Direction des Patients, Usagers et Associations, Assistance Publique-Hôpitaux de Paris, Paris, France}

Objective: Time spent in hospitals is complex and entails a number of distinct phases that fluctuate depending on many variables. Attempts to understand patients' experiences often involve focusing on their needs using self-evaluation, but this does not clearly highlight the complexity of coping. Questionnaires based on telephone surveys and emails do not facilitate a sufficient assessment of the coping effort. However, when patients express themselves through spontaneous narration, different dimensions may emerge in their experience at the hospital. This qualitative study explores the various forms of coping among patients with a hospital experience.

Methods: Interviews were conducted with 75 patients in six hospital departments. Transcripts from interviews were thematically analyzed and a conceptual, multidimensional model was developed to explain the relationship between patient experience and coping complexity.

Results: Patients used a set of about 50 different terms to describe their experiences in the hospital. They described with the greatest number of words the aspects that triggered their stress or distress and forced them to cope. Stress resulting from the experienced situation was classifiable into five dimensions: trauma, environment, medical, interpersonal affective, and social impact, which constitute invariants that may require individual complex coping strategies.

Conclusion: Patient experience is hard to evaluate, and this represents a permanent challenge for medical teams. Considering the five coping dimensions delineated in this study may be helpful in improving the patient's hospital experience.

Keywords: patient experience, stress, biopsychosocial model

\section{Introduction}

Hospitalization is a complex situation that leads to situations of distress. A hospitalization experience affects all patients, including those who do not have any psychological difficulty. For most patients, this experience is not explicitly expressed, being outside the scope of real mental suffering.

There is a need to configure care services according to the needs of the patient rather than those of the health care system. ${ }^{1}$ However, this configuration is usually linked to a particular disease. On the emotional level, patients develop positive and negative feelings that are often not related to the biomedical aspect of care. In addition, there is a discrepancy between the perception of medical teams and the patients. ${ }^{2}$ Thus, when medical teams face a stressful situation, health care providers may assess the situation according to their own beliefs, sense of control, constraints, personal resources, social networks, and individual coping styles. ${ }^{3}$ This representation by health care providers
Correspondence: Gérard Reach Service d'Endocrinologie, Diabétologie, Maladies Métaboliques, Hôpital Avicenne, I 25 route de Stalingrad, 93000 Bobigny, France

$\mathrm{Tel}+33$ | $48955 \mathrm{I} 58$

$\mathrm{Fax}+33$ । 48955560

Email gerard.reach@avc.aphp.fr 
often differs from patients' coping strategies, ${ }^{4}$ which allow them to better tolerate their disease ${ }^{5}$ and refer to "the specific efforts, both behavioral and psychological that people employ to master, tolerate, reduce, or minimize stressful events". ${ }^{6}$

Well-being during the hospitalization experience may be related to an understanding by the medical teams of the coping efforts made by the patient. ${ }^{7}$ The patient-centered care can be effective as his/her views, opinions, beliefs, and attitudes are taken into account. ${ }^{8}$ However, concerns expressed by patients are usually focused only on one specific aspect.

The construction of a holistic model that matches with the particular context of a particular hospital and is based on a collection of spontaneous narration expressed during the stay of a given patient would provide more comprehensive insights into the reality. This qualitative study was therefore aimed at exploring patients' perspectives on coping with hospitalization through nondirective interviews. The following issues were specifically addressed: 1) What are the coping situations for patients during the hospitalization experience? 2) Do patients use the same groups of words to express their coping efforts? 3) What dimensions of coping do participants systematically report in their stories? The aim of this article is to show that coping is multidimensional.

\section{Methods}

\section{Setting}

This study was conducted by the DPUA (Direction des Patients, Usagers et Associations) of Assistance PubliqueHôpitaux de Paris (AP-HP), which regroups 37 university hospitals in Paris, France, and was directed by DF within the context of a reflection on the concept of hospitality. Patients included in the study were met by the two interviewers at the end of their stay in the hospital. The intervention consisted of a nondirective interview at the bedside. Interviews were proposed to the patient by their health care provider. The trial was conducted in six medical departments: Outpatient visit, Endocrinology, Internal Medicine, Obstetrics, Geriatrics and Emergencies. These departments belong to four hospitals: Avicenne, Broca-La Rochefoucauld-La Collégiale, Cochin, and Hôpital Européen Georges Pompidou. These hospitals are located in the city center and suburbs of Paris, France, with different populations considered homogeneous within the entire population of the AP-HP hospitals.

\section{Sampling}

We recruited patients on the advice of the physician in charge. Patients were recruited over a period of 6 months.
They agreed to sign a consent form. Twenty-seven men and 48 women were randomly selected based on their medical condition. Patients seeming to be unable to understand the purpose of the study, concerned by mental health issues, or under 18 years were excluded. From the 75 men and women invited to participate, 57 agreed to have their responses transcribed verbatim for analysis.

\section{Data collection}

Two researchers conducted face-to-face interviews: a PhD in clinical psychology and a licensed clinical psychologist. They began with an introduction of the project's objective. Discussions with the patients were aimed at listening to the story of their experience in the hospital. The interviews collected spontaneous expressions of feelings, highlighted events, and points of view that were illustrated with specific examples. Table 1 shows the types of preliminary questions and redirecting sentences. There was an audio recording transcribed anonymously. Notes taken at the time of the interview were included in the analysis.

Interviews were conducted with 75 patients. Interviews lasted 45-90 minutes. The patient demographics were representative of participants admitted to Parisian hospitals. The average age of the patients was 52 years, with a range

Table I Questions from the nondirective interview schedules

- Why did you come at the emergency?

- So then what?

- Then you went in a "box"?

- Reformulation: they took your biological test results?

- For example?

- Is this an important moment?

- In your journey, have there been times when you were more anxious? Do you have anything else to add?

- Can you tell me about your background in the department?

- So for you, it was?

- Why are you back to the exam room?

- So you have already been here several times, and your children as well?

- For you and your loved ones?

- And both your parents were in the hospital?

- ... people you know?

- What more can you tell me about the cause of event?

- Do you have anxiety each time you enter?

- Especially when it resonates with?

- And all along the way?

- So what are the results?

- Was he also the doctor of your sister?

- You had the impression that you ...?

- And it lasted how long?

- You mentioned a lot of feelings when you talk about your experience. 
between 25 and 100 years. The majority were born in France and spoke French at home. Forty had a job, 34 were retired or unemployed, and one patient's profession remained unknown.

\section{Data analyses}

Data analysis was performed following the principles of the method of thematic analysis. ${ }^{9}$ The transcripts and notes were read and reread to identify initial semantic categories and registrars were coded via word occurrences. Categories were then proposed and revised as further data were collected and analyzed. Class identification was based on the data and was influenced by literature and background reading. The themes that emerged from the data were consistent with the categories based on theoretical classifications. The collection and analysis of data continued until saturation of the data occurred. Throughout the analysis, GR, DF, and CM discussed and agreed on the interpretation of the data.

The study complies with the guidelines of the RATStive qualitative research.

\section{Ethics}

The study was approved by the Evaluation Committee of Ethics of Biomedical Research projects CEERB Paris Nord. Participants provided written consent. Anonymity of all patients was guaranteed.

\section{Results}

\section{Expression of personal stories}

Patients seemed motivated by talking to someone who listened to them because they had not been able to tell the story of their experiences at the hospital. They were also motivated by a desire to improve services and support medical care for other patients who would come after them. Some were also motivated to complain about their experience and medical teams.

Participants seemed generally determined to explain what they were experiencing. Most of the time, patients described episodes where they encountered large difficulties with which they had to cope.

\section{Identifying five dimensions in patient stories}

From the patients' verbatim responses, we identified a set of about 50 different terms to describe their experiences at the hospital. Among the elements of experience, they designated a series of controllable factors but also some others beyond their control. They described with the greatest number of words the aspects that pushed them to become distressed and forced them to make an effort to cope.

The data analysis reported below resulted in five main areas: trauma, environmental, medical, interpersonal and affective, and social impact. A conceptual model was developed from the data to illustrate the relationship between the occurrence of words in the related story of hospitalization and the coping effort of the patient.

\section{Medical dimension}

One of the demanding dimensions in terms of efforts to cope, which was frequently mentioned, concerned medical intervention. Patients described, with varying intensity, medical events as a stressor:

No matter how many tests the doctor ran, we are still not quite sure that we have the results. [Urban man 1]

So she made a diagnosis. She said that they should give me medication to ease the pain. The nurse returned and put me on drips. [Urban man 1]

Well everything went well. But there are some tests that are difficult. Very difficult. [Urban woman 1]

It was complicated. They operated on this finger; listen to me, four times. So I had a prosthetic finger. They tried to arrange the prosthesis for me a second, third, fourth time. Then they took everything out and gave me an arthrodesis. [Urban woman 1]

The words most often used to evoke the medical dimension were: "physicians, doctors, nurses, illness (description), treatment, childbirth, giving birth, ill, operation, examination, medicine, taking blood, results, analysis".

\section{Trauma dimension}

Another dimension mentioned in the narration of the patients was trauma as the leading cause of arrival at hospital. The concept of trauma is, in its nature, either a stress, pain, or distress that generates a decision by the patient or by relatives, resulting in hospitalization. A man suffering from irritable bowel syndrome described his experience:

I was about to have an acetone crisis as I had a gastroenteritis crisis, so I had a stomach crisis. All I need is some drips.... to ease the pain. [Urban man 2]

There's a problem with my drips, they have to change them because I'm about to pass out, this is an emergency! [Urban man 2]

A man suffering from irritable bowel syndrome described his experience before and after the pain relief: 
That gave me some relief. But still the same anxiety. I left with the same stress (...) I came back with the same stress. The same stress. [Urban woman 2]

The terms most often used to refer to the dimension of trauma were within verbatim: "problem, it hurts, pain, fear, anxiety, it's difficult, stress".

\section{Environmental dimension}

Patients also referred to the environment within the hospital as a key dimension in the patient care experience:

Well, I would have preferred to be in a room by myself but that's alright (...). Because when we're alone (silence). There's always privacy in the hospital that we should still respect. [Urban woman 3]

And afterwards, I was taken in a small box (silence) to two rooms separated by a partition (...). And there, after that, I was taken to another waiting room opposite from here it seems, on the same floor, and I waited there for a very long time. And I am a bit sleepy. The hospital is already noisy, noisy in general. When night comes, the human sounds get smaller but that makes other noises appear, like the fans, the mechanical noise that comes from I don't know where. [Urban man 3]

The terms most often used to evoke the environmental dimension were within verbatim: "wait, appointments, home, room, bedroom, sick room, consultation, call, exit/exit, it's long (time), sleeping".

\section{Interpersonal affective dimension}

Patients were clear about the need to have close contact with a person, such as another patient in the room or in the service. Often the figure of the kind doctor was reiterated in the transcripts. Interpersonal relationships, including those that were emotional, constituted an essential aspect of life in the hospital:

When my parents came, when I called them, I had less pain. The pain was always there but having my mother by my side reassured me, to have my friend on the phone, it was reassuring. [Urban man 1]

What's great about Dr B is that when we talk, he listens to me. He considers my suggestions. [Urban woman 4]

That's important. A doctor who listens to you can explain things to you, that's it...he explains things to you using understandable terms. [Urban woman 4]

The terms most often used to refer to the interpersonal dimension were within verbatim: "Dr (name), Nurse (name), home call, child call, understanding, telephone, was explained to me, reassure, reassuring baby, my doctor, a doctor, my husband, gentle".

\section{Social impact dimension}

Participants described an important social dimension, implying some form of physical, moral, professional, and/ or familial transformation. For these patients, coming to the hospital represented an event in the course of life, sometimes resulting in a fracture which exceeds the medical treatment:

At home, I'm the one in charge. So I left all the responsibilities to my husband. I told him "now you're taking over, I am not going to be there (...)" I told him "get yourself together, go back to the children because they are stressed. They are not there for you. You're the one who's supposed to be there for them". [Urban woman 6]

Then I left after I had a hernia operation. After that I couldn't work anymore but I would have liked to continue because I was feeling well. I was worried about my daughter. I wonder if she'll be all alone, aie aie aie. They will have to place her in a home or maybe the family will take her. We don't know. We always say that and then sometimes the family really wants it but they have their troubles as well. [Urban woman 6]

That's what's getting me all tensed up as well. It's returning home. When we see their plans. Because for now we are removed from their control. Before, I could prepare a small meal like that without much trouble. I had a lot of difficulties in recovering my taste (...) I had an obsession. I always looked for more flavorful products. Because I was fed through a tube for several months (...) I ate no oysters a year and a half ago. They would prepare a little treat. A little bit of white wine. You know, the little things are part of the accompaniment. [Urban man 4]

The terms most often used to evoke the social dimension were within verbatim: "to eat, child, work, home, baby".

\section{Proposed conceptual model}

As shown in Figure 1, we suggest that the patients' experienced situations may be described according to five distinct dimensions. These dimensions would constitute invariants in the experience of all the participants and would be linked to the effort required for individual complex coping strategies. Thus, the coping experience is complex because patients may make efforts in several dimensions at a time: according to this model (Figure 1), coping includes a series of efforts and 


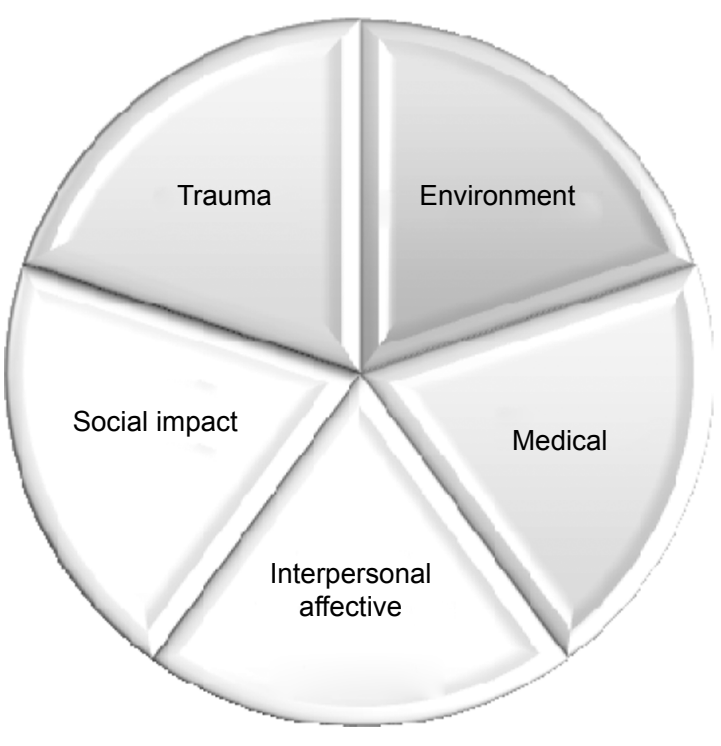

Figure I The five dimensions of coping based on thematic analysis.

strategies related to dimensions that all participants narrate more or less in their stories: trauma, environment, medical, interpersonal affective, and social impact.

\section{Discussion}

This qualitative study found that the range of experiences was more varied than medical teams may expect and distinguished five separate domains. Thus, these different types of coping may enrich our imagination on how to organize interventions aimed to reduce patient distress during hospitalization.

The experience of patients during their time in the hospital described herein is consistent with the cognitive models for stress management and coping strategies. ${ }^{4,6}$ Participants in this study appeared to be in a waiting and somewhat passive situation. However, they all described their behavior as a response to trauma and an act to influence internal or external stressors, according to the circumstances of their health condition, and to their feelings and beliefs at the time.

In their entirety, forms of the stories were long descriptions of the health event, composed of external stressors and emotions experienced, linked to the level of internal stress. The participants in our study essentially described what played a principal role and what had a direct impact on these stressors in their experiences. Patients never clearly explained their coping strategies, and their personal points of view did not emerge until the summarizing conclusion. They only wanted to share their feelings and be understood by their listeners.

Reflections regarding the services at the hospital, including the relationship with the doctor, were found to be effective, ${ }^{10}$ but the mechanisms of action for the patient remains an open issue. Therefore, future interventions for the patient and lifestyle in medical practice should consider containing appropriate individual support processes including dimensions as described in this study. New frameworks for the characterization and design of services in the hospital could incorporate as individual factors the five dimensions described herein, and the complexity of coping construction by the patient.

\section{Limits of the study}

Demographic factors and medical events of the participants were representative of the experiences of hospitalized patients. However, our results may not be representative of all patients. Patients who participated in this study may not perfectly constitute a representative sample, so that our results may not be applicable to a larger population without complementary interviews. There were a few patients who agreed to participate and those who agreed were recruited. This again limited our findings to those who were physically present on days when interviews were possible in the medical services.

Likewise, medical services that participated were interested in discussing the patients' experiences in the context of practice in order to identify appropriate measures for patients. This may not be the case in other medical departments. Finally, face-to-face interviews were a simple choice in order to limit the loss of detail, such as nonverbal clues. However, the interviewer may have potentially influenced the response of participants as the latter may have been more inclined to give acceptable answers to a person wearing a white coat.

Therefore, this study should be considered as a pilot, and further studies are needed to explore the credibility, transferability, and confirmability of its findings.

\section{Conclusion}

We suggest that services to improve the well-being of a patient at the hospital should note the multidimensional nature of coping as described in this study, which allows for a better understanding of the complex processes and interactions between the patient and the hospital. The medical dimension is only one of the many dimensions that have an impact, or may be affected by the patient's coping experience. While participants in this study were all under medical care, the environmental and the interpersonal dimensions were very important in their expressions, as was social impact. Finally, initial effects of trauma trigger a series of emotional 
states and actions of adaptation that strongly influence the doctor-patient relationship.

Maintaining an acceptable experience for patients in the hospital is a complex and constant challenge for medical teams. The main stress factor that affects the behavior of the patient is the medical event moderated by the intervention of health care providers treating the causes of the trauma. Our results are consistent with theoretical models of stress management and point to five dimensions of coping. Practitioners can help patients achieve a more satisfying emotional experience by offering targeted actions based on these five dimensions.

\section{Acknowledgments}

We express our gratitude to the patients and medical departments at the AP-HP (Assistance Publique-Hôpitaux de Paris) who participated in this study.

\section{Author contributions}

All authors contributed to the conception and design of the study as well as the interpretation of data. DF and CM conducted the interviews. DF wrote the first draft of the manuscript. GR contributed to revising the manuscript. All authors contributed toward data analysis, drafting and revising the paper and agree to be accountable for all aspects of the work.

\section{Disclosure}

The authors report no conflicts of interest in this work.

\section{References}

1. Gallacher K, Morrison D, Jani B, et al. Uncovering treatment burden as a key concept for stroke care: a systematic review of qualitative research. PLoS Med. 2013;10:e1001473.

2. Institute of Medicine (US). Crossing the Quality Chasm: A New Health System for the 21st Century. Washington, DC: National Academy Press; 2001. Available from: www.nap.edu/openbook.php?isbn=0309072808. Accessed September 15, 2014.

3. Di Battista G, Bertolotto A, Gasperini C, Ghezzi A, Maimone D, Solaro C. Multiple Sclerosis State of the Art (SMART): a qualitative and quantitative analysis of therapy's adherence, hospital reliability's perception, and services provided quality. Mult Scler Int. 2014;2014:752318.

4. Taylor S; Psychosocial Working Group. Coping strategies [webpage on the Internet]. MacArthur: Research Network on SES \& Health [revised 1998]. Available from: http://www.macses.ucsf.edu/research/ psychosocial/coping.php. Accessed January 5, 2015.

5. Ridgeway JL, Egginton JS, Tiedje K, et al. Factors that lessen the burden of treatment in complex patients with chronic conditions: a qualitative study. Patient Prefer Adherence. 2014;8:339-351.

6. Folkman S, Lazarus RS. An analysis of coping in a middle-aged community sample. J Health Soc Behav. 1980;21:219-239.

7. McKenzie SH, Harris MF. Understanding the relationship between stress, distress and healthy lifestyle behavior: a qualitative study of patients and general practitioners. BMC Fam Pract. 2013;14:166.

8. Kleiner-Fisman G, Gryfe P, Naglie G. A patient-based needs assessment for living well with Parkinson disease: implementation via nominal group technique. Parkinsons Dis. 2013;2013:974964.

9. Braun V, Clarke V. Using thematic analysis in psychology. Qual Res Psychol. 2006;3:77-101.

10. Chabrol H, Callahan S. Mécanismes de Defense et Coping [Defense Mechanisms and Coping]. 2nd ed. Paris: Dunod; 2013. French.
Patient Preference and Adherence

\section{Publish your work in this journal}

Patient Preference and Adherence is an international, peer-reviewed, open access journal that focuses on the growing importance of patient preference and adherence throughout the therapeutic continuum. Patient satisfaction, acceptability, quality of life, compliance, persistence and their role in developing new therapeutic modalities and compounds to optimize

\section{Dovepress}

clinical outcomes for existing disease states are major areas of interest for the journal. This journal has been accepted for indexing on PubMed Central. The manuscript management system is completely online and includes a very quick and fair peer-review system, which is all easy to use. Visit http://www. dovepress.com/testimonials.php to read real quotes from published authors. 